\title{
Effects of r-HuEPO on the biophysical characteristics of erythrocyte membrane in patients with anemia of chronic renal failure
}

SHI HONGLIAN, FAJUN Y ANG, BAOLU Z HA O, WENJUAN XIN ${ }^{1}$

Institute of Biophysics, Academia Sinica, Beijing, China.

\begin{abstract}
Using electron spin resonance (ESR) spin labeling technique, we have studied the conformation of sulfhydryl groups(-SH) binding sites in membrane proteins and membrane fluidity of red blood cells (RBCs) from two groups of patients with anemia of chronic renal failure (ACRF). One of the groups is composed of patients who were untreated with recombinant human erythropoietin(r-HuEPO), and the other is composed of patients who were treated with $\mathrm{r}$-HuEPO. The results indicated: 1) the conformation of $\mathrm{SH}$ group binding site in RBC membrane proteins from former group was different from those of health people. 2) the fluidity in the region near the surface of RBC membrane from former group was lower than those of healthy people. 3) However, the above biophysical properties of $\mathrm{RBC}$ membrane from later group were normal. We concluded that RBC membrane in patients with ACRF was abnormal, and the treatment of r-HuEPO may promote the production of normal RBCs, thus ameliorate the biophysical properties of RBCs from the patients with ACRF.
\end{abstract}

Key words: ESR Spin labeling, r-HuEPO, ACRF, $R B C s$.

\section{INTRODUCTION}

Anemia is an inevitable and serious complication of renal insufficiency and the

1. Corresponding author 
ESR, erythrocytes and anemia of chronic renal failure

most important factor limiting optional rehabilitation in this group of patients[1]. The major mechanisms that have been recognized to contribute to the anemia of chronic renal failure are shortened red blood cell survival[2], decreased erythropoietin(EPO) production[3], retained inhibitors or toxic metabolites in CRF that inhibit erythropoiesis[4], and other factors[5-8]. Since r-HuEPO became available for clinical trial, preliminary reports have shown its effectiveness in correcting the anemia of not only patients on dialysis[9, 10], but also pre-dialysis patients[11]. Patients who received active $\mathrm{r}-\mathrm{HuEPO}$ showed a dose-dependent rise in hematocrit, an increase of RBC mass and patients' maximal oxygen consumption during exercise. But, neither the biophysical characteristics of RBC membrane of patients with ACRF, nor the ffects of $\mathrm{r}-\mathrm{HuEPO}$ on the membrane characteristics have been reported. The membrane of $\mathrm{RBC}$ is important to its function. The reason why RBCs of patients with ACRF have shortened life span may be associated with their membranes. Using ESR spin labeling technique, we studied the effects of r-HuEPO on the conformation of SH group binding sites in membrane proteins and the membrane fluidity of RBCs of the patients on the sub-molecular level.

\section{SUBJECTS, MATERIALS AND METHODS}

\section{Subjects studied}

Group 1. Twelve patients, seven women and five men, aged 18 to 69 , from 4 th Internal-medicine Department, Beijing 514 Hospital. Serum creastinine levels ranged from 132 to $700 \mu \mathrm{mol} / \mathrm{L}$. All patients were anemic, hemoglobin ranged from 3.9 to $9.4 \mathrm{~g} \%$. Of these patients, two were on hemodialysis, two without any treatment, others were treated on account of their etiology of anemia of CRF (chronic glomerulonephritis, polycystic kidney disease, chronic tubular interstitial, chronic nephritis). No patient was treated with r-HuEPO.

Group 2. Nine patients, three women and six men, aged 30 to 72, from 4th Internal-medicine Department, Beijing 514 Hospital. All patients were anemic and treated with r-HuEPO. r-HuEPO was administered intravenously three times a week at a dose of 50,100 or $150 \mathrm{U} / \mathrm{Kg}$ until the hematocrit reaches $30 \%$, and the dose was subsequently adjusted in order to maintain the hematocrit at approximately 35\%. Hemoglobin ranged from 5.0 to $7.4 \mathrm{~g} \%$ before treated with r-HuEPO. After treatment with r-HuEPO, hemoglobin ranged from 8.3 to $13.0 \mathrm{~g} \%$ (the average was $11.1 \mathrm{~g} \%$ ). The normal hemoglobin level is $11.0-13.0 \mathrm{~g} \%$.

Group 3. For the controls, ten age-matched healthy subjects with normal renal function were selected.

\section{Chemicals}

Spin labels 3-Maleimide-proxyl(M(I)), 5-doxyl stearic acid (5-DOXYL) and 16-doxyl stearic acid (16-DOXYL) were purchased from Sigma Chemical Co. . r-HuEPO was produced by AEGEN Company (USA). All other chemicals made in China were AR grade.

\section{Cell preparation}

The freshly drawn, heparinized blood from patients or healthy people was centrifuged at $800 \mathrm{~g}$ for $5 \mathrm{~min}$ at $277 \mathrm{~K}$. The plasma and the buffy coat were removed. Then, the collected RBCs were washed three times with PBS $(0.05 \mathrm{~mol} / \mathrm{L}, \mathrm{pH} 7.4$ Phosphate Buffered Saline).

\section{Spin labeling of $R B C$ membranes with fatty acids and maleimide}


An appropriate amount of spin labels was dissolved in a little anhydrous alcohol and diluted with PBS to $5.0 \mathrm{mmol} / \mathrm{L}$. A mixture containing red blood cells $\left(5 \times 10^{7}\right.$ cells $\left./ \mathrm{ml}\right)$ and spin labels $(0.015 \mathrm{mmol} / \mathrm{L}$ for fatty acid spin labels and $0.15 \mathrm{mmol} / \mathrm{L}$ for maleimide) was incubated at $310 \mathrm{~K}$ for $30 \mathrm{~min}$ for fatty acid spin labels and two hours for maleimide. Then, the cell suspension was centrifuged at $800 \mathrm{~g}$ for $5 \mathrm{~min}$ at $277 \mathrm{~K}$, and the resulting RBCs were rinsed five times with PBS. No signal of free spin labels was detected from the last supernatant. This showed that the ESR spectra obtained in the experiment were solely contributed by those spin labels which had been labeled in the RBC membranes.

\section{ESR measurement}

The labeled RBCs were sucked into quartz capillaries, the ESR spectra were recorded using a Varian E-109 spectrometer, with microwave power $20 \mathrm{~mW}$, modulation amplitude $0.1 \mathrm{mT}$, scan width $10 \mathrm{mT}$, and time constant 0.128 sec. The temperature was $298 \mathrm{~K}$. The calculating method of order parameters (S) was the same as described in Reference 12, and that of the ratio of weakly immobilized component to strongly immobilized one (W/S) of the ESR spectra as in Reference 13.

\section{Statistical analysis}

Calculations of statistical signiflcance of difference were made using the two-tailed Student's t-test.

\section{RESULTS}

Changes in conformation of sulfhydryl group binding sites of RBCs from patients with ACRF

Maleimide labels can specifically bind to SH groups of proteins[14]. A representative ESR spectrum of M(I) labeled red blood cells is shown in Fig 1. From the

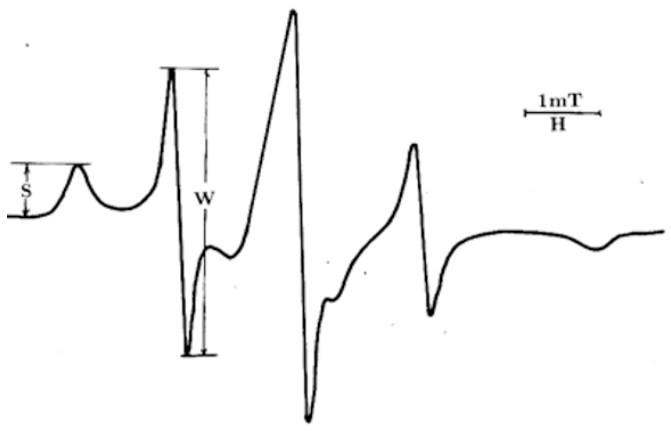

Fig 1. ESR spectrum of erythrocytes labeled with 3-Maleimideproxyl. See text for ESR measurement conditions.

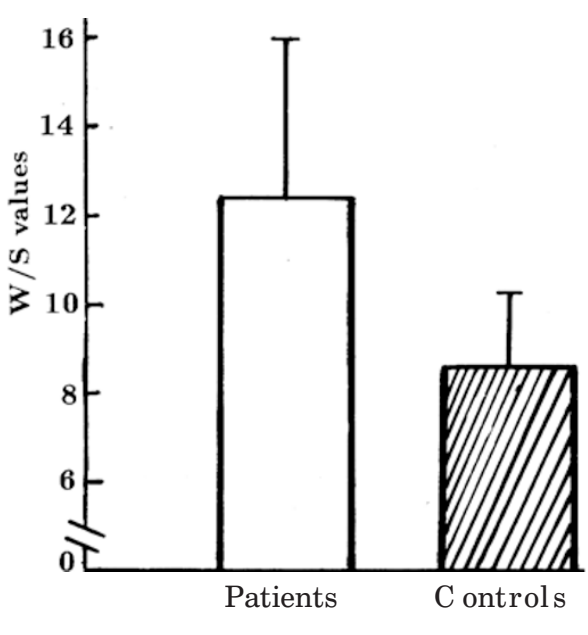

Fig 2. Effect of anemia of $\mathrm{CRF}$ on the $\mathrm{W} / \mathrm{S}$ values of spin labeled erythrocytes. There was significant difference between two groups $(\mathrm{P}<0.05)$. 
ESR, erythrocytes and anemia of chronic renal failure

result shown in Fig 2 , it could be seen that the W/S values of labeled RBCs of the patients (group 1) were higher than those of controls $(\mathrm{P}<0.05)$. The result indicated that when patients suffered from ACRF, the number of less deeply buried SH groups increased or, the number of deeply buried ones decreased, resulting in a higher level of $\mathrm{W} / \mathrm{S}$. The phenomenon, in fact, was a result of membrane protein conformation changes.

Recovery effect of $r-H u E P O$ on the conformation of sulfhydryl groups of $R B C$ membrane of patients with $A C R F$

The spin labeling result of RBCs from the patients (group 2) were shown in Fig 3. Though the mean $\mathrm{W} / \mathrm{S}$ value of sulfhydryl group binding sites of RBC membrane of patients with ACRF was higher than that of control, there was no significant difference of the W/S values between patients and controls $(\mathrm{P}>0.05)$. This indicated that, when the patients were treated with r-HuEPO, the conformation of SH groups of membrane proteins of RBCs in the patients tended to be normal.

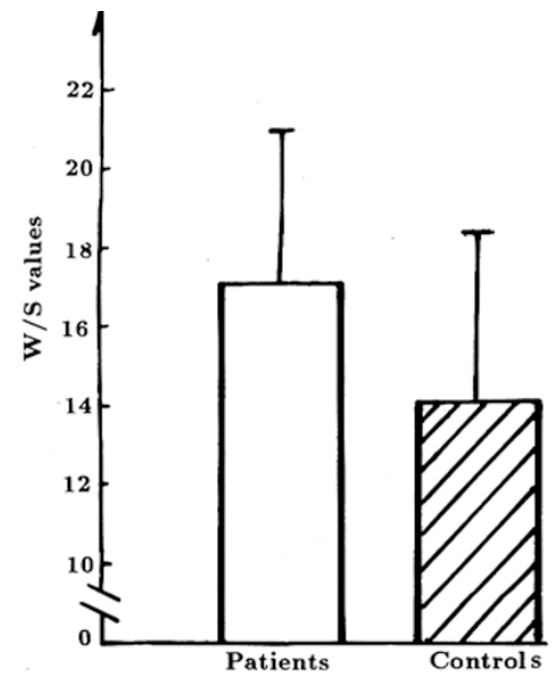

Fig 3. Effect of $r-H u E P O$ on the W/S values of spin labeled erythrocytes. There was no significant difference between two groups $(\mathrm{P}>0.05)$. The results from the ESR spectra recorded using a JEOL ESR spectrometer.

\section{Changes in membrane fluidity of erythrocytes from patients with ACRF}

Consisting of a nitroxide group usually attached to a long chain fatty acid and being able to partition into lipid-containing membrane, fatty acid spin labels can be used to examine the relative orientation and motion of regions within membrane bilayers[15]. The representative ESR spectra of spin labeled RBCs of patients with 5-DOXYL and 16-DOXYL were shown in Fig 4 . The membrane order parameter(S) values of the patients (group 1) and control RBCs labeled with 5-DOXYL are shown in Fig 5. The result showed that the $\mathrm{S}$ values of patient RBCs labeled with 5-DOXYL were larger than that of controls. However, there was no significant 
Shi HL et al
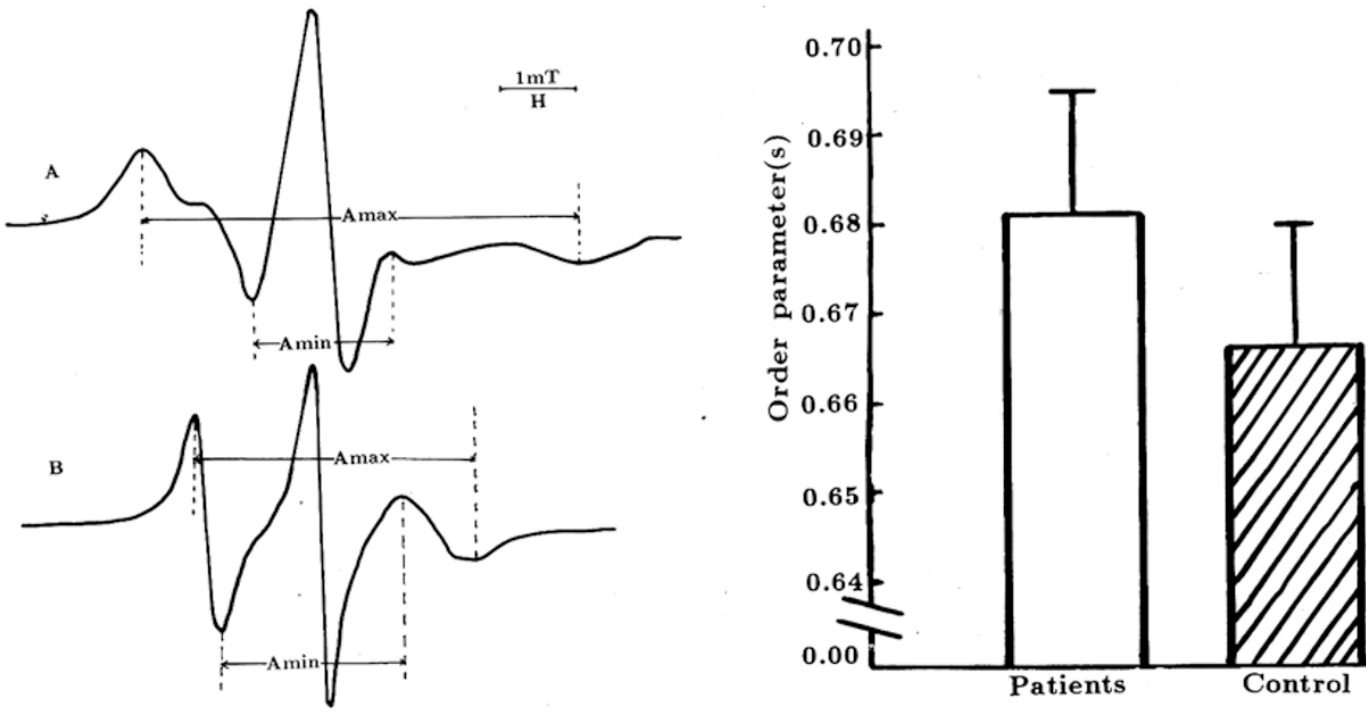

Fig 4. ESR spectra of erythrocytes labeled with 5-DOXYL (A) and 16DOXYL (B). See text for ESR measurement conditions.
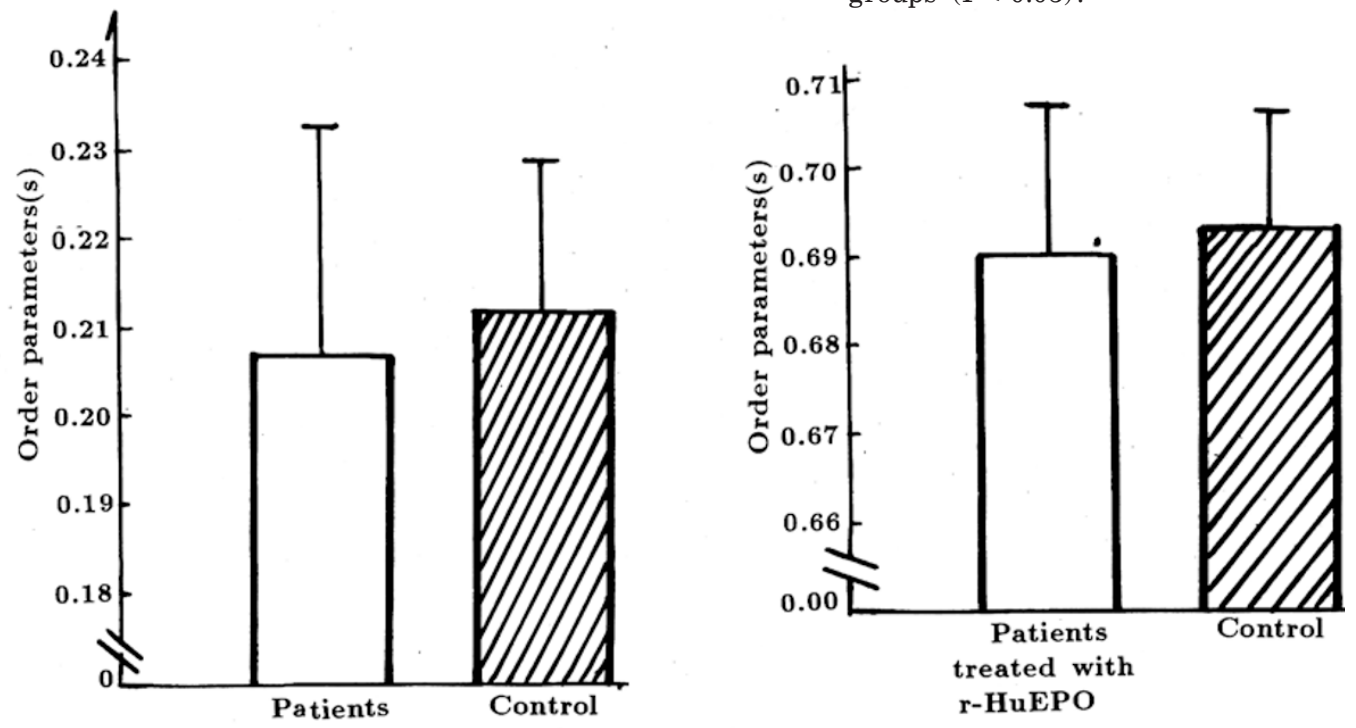

Fig 6. Effect of anemia of CRF on the order parameter of labeled erythrocytes with 16-DOXYL. There was no significant difference between two groups $(\mathrm{P}>0.05)$. 
ESR, erythrocytes and anemia of chronic renal failure

difference of the $\mathrm{S}$ values from RBCs labeled with 16-DOXYL between patients and controls (Fig 6). It indicated that the fluidity near the surface of RBC membrane from patients with ACRF decreased, however the membrane fluidity near the nonpolar end of phospholipids of RBC membrane from the patients were almost the same as that of normal controls.

\section{Recovery effect of $r-H u E P O$ on the membrane fluidity of RBCs from patients with ACRF}

Fig 7 showed the values of the order parameter (s) of RBCs labeled with 5-DOXYL of the patients (group 2). By statistical analysis, there was no significant difference of the $\mathrm{S}$ values of RBCs between patients and healthy persons $(\mathrm{P}>0.05)$. The result indicated that, after treatment with $\mathrm{r}-\mathrm{HuEPO}$, the $\mathrm{RBC}$ membrane fluidity of patient inclined to be normal.

\section{DISCUSSION}

From our results, the biophysical characteristics of RBC membrane were changed in the patients with ACRF who were not treated with r-HuEPO as compared with healthy subjects. There may be several factors inducing the abnormal biophysical characteristics. Firstly, since the antioxidant systems, such as superoxide dismutase(SOD), catalase, glutathione peroxidase, Vitamin E, Vitamin C, GSH, and trace elements in the serum of patients with ACRF were abormal, the patients' RBC membranes had an increased susceptibility to lipid peroxidation [16,17]. Miguel et al[18] have found that the amount of malondialdehydes (MDA), one of the final products of lipid peroxidation, in RBCs in a group of patients affected by ACRF is higher than that of normal. It indicates that the RBC membrane of the patients has been defected by lipid peroxidation. Membrane lipid peroxidation can change the components of membrane lipids, moreover, the intermediates formed during lipid peroxidation can cause damage to membrane proteins and MDA can cross-link membrane proteins[19]. As a result, the membrane fluidity is changed, and the conformation of SH group binding sites of membrane proteins is altered. Secondly, the serum lipids in patients with ACRF is also abnormal[20]. This may influence the membrane lipid composition of the RBCs and cause lipid peroxidation in RBC membrane. Thirdly, the amount of toxic metabolites in the patient internal-environment is increased, because the important result of renal failure is that the ability of clearing away toxic substance is decreased. It is the evidence that transfusion of normal red blood cells into uremic patients results in a shortening of survival of the transfused cells while transfusion of red blood cells from patients with CRF into nonuremic subjects is associated with normalization of red blood cells survival[21]. These toxic metabolites may cause damage to the membrane directly or indirectly.

Many experimental evidences have shown that $\mathrm{r}$-HuEPO can be effective and safe in ameliorating anemia of chronic renal failure. From our experimental results, 
it appears that $\mathrm{r}$-HuEPO has recovery effect on the conformation property of SH group binding sites of membrane protein and membrane fluidity of RBCs in patients with ACRF. The target for EPO is the committed erythroid progenitor cell which, when stimulated differentiates into the morphologically recognized normoblast. EPO also amplifies the numbers of this early erythroid progenitor population. Cotes et al[22] suggested that the ACRF was predominantly induced by failure to increase endogenous production of erythropoietin and thus red blood cell production. When erythropoiesis is stimulated by r-HuEPO in subjects with increased iron stores, these iron stores can be mobilized for new hemoglobin synthesis, then more new born red blood cells are produced. Though it was notable that the shortening of red blood cell survival was not corrected by administration of erythropoietin despite correction of anemia[22], the degree of lipid peroxidation in the cells entering the blood cycle may be not high in not long time. In fact, Dong et al[23] have reported that the level of MDA in RBC membrane of the patients with ACRF treated with r-HuEPO is significantly lower than that of patients who were untreated with r-HuEPO, and the level of SOD in whole blood of the patients is increased after treatment of $\mathrm{r}-\mathrm{HuEPO}$. In addition, new born RBCs bring more oxygen to the blood circle and improve the internal-environment. As a result, the biophysical characteristics of red blood cells appeared normal.

In conclusion, anemia of $\mathrm{CRF}$ can result in abnormalities of conformation of $\mathrm{SH}$ group binding sites in membrane protein and fluidity of RBCs membrane, and the treatment of r-HuEPO on patients with ACRF seems to be beneficial to the membrane biophysical characteristics.

\section{ACKNOWLEDGEMENT}

This research was supported by a grant from Academia Sinica. We thank Dr. Deng Xiaobing, Director of Dept. 4, 514 Hospital of PLA, Beijing, providing blood samples.

\section{REFERENCES}

[1] DePalma JR. Uremia, isn't it mostly anemia? Contemporary Dialysis and Nephrolody 1987; 8:28-38.

[2] Shaw AB. Haemolysis in chronic renal failure, Br Med J 1967; 2:213-215. .

[3] Admson JW , Eschbach JW, Finch CA. The kidney and erythropoies. Am J Med 1968; 44:72533.

[4] McGonigle RJS, Wallin JD, Shadduck RK, Fisher IW . Erythropoietin deficiency and inhibition of erythropoies in renal insufficiency. Kideny Int 1984; 25:437-44.

[5] Serickland ID, Chaput De SDM, Bovlton FE, Francis B, Roubikova J, Waters JI. The therapeutic equivalence of oral and intravenous iron on renal dialysis patients. Clin Nephrol 1977; 7:55-7.

[6] Hampers CL, Streiff R, Nathan DG, Snyder D, Merrill JP. Megaloblastic hematopoiesis in uremia and in patients on long term hemodialysis. N Eng J Med 1967; 276:551-4.

[7] Wills MR, Savory J. Aluminum poisoning: Dialysis encephalopathy, steomalacia, and anemia, Lancet 1983; 1:29-34. 
ESR, erythrocytes and anemia of chronic renal failure

[8] Barbour GL. Effects of parathyroidectomy on anemia in chronic renal failure. Arch Inter Med 1979; 139:889-91.

[9] Eschbach JW, Egrie JC, Downing MR, Browne JK, Adamson JW. Correction of the anemia of end-stage renal disease with recombinant human erythropoietin. N Engl J Med 1987; 316:73-8.

[10] Winearls CD, Oliver M J, Reid C, Downing MR, Cotes PM. Effects of human erythropoietin derived from recombinant DNA on the anemia of patients maintained by chronic haemodialysis. Lancet 1986; 2:1175-8.

[11] Victoria SL, Richard LD, Donald Z, Peter TK, Robert A, Paul P, Terry F. Recombinant human erythropoietin treatment on predialysis patients. Annals of Internal Medicine 1989; 110:108-14.

[12] Zhao BL, Zhang QG, Zhang JZ, Xin WJ. Studies on the membrane fluidity of the hamster lung normal cell V and cancer cell V-B with fatty acid spin labels. Kexue Tongbao 1983; 28:392-9.

[13] Xin W J, Zhao BL, Zhang JZ. Studies on the property of-SH binding site on the lung normal and cancer cell membrane of Chinese hamster with maleimide spin labels. Scientia Sinica (Series B) $1984 ; 27: 1008-14$.

[14] Berliner LJ. Spin labeling. Ann NY Acad Sci 1983; 414:153.

[15] Jost P, Libertin LJ, Hebert VC, Briffith $\mathrm{OH}$. Lipid spin labels on lecithin multilayers. A study of motion along fatty acid chains. J Mol Biol 1971; 59:77-83.

[16] Richard MJ, Arnand J, Jurkovitz C, Hachache T, Meftahi H, Laporte F, Foret M, Farier A, Cordonnier P. Trace elements and lipid peroxidation abnormalities on patients with chronic renal failure. Nephron 1991; 57:10-15.

[17] Shainkin-Kestsnbaum R, Caruso C, Berlyne GM. Reduced superoxide dismutase activity in erythrocytes of dialysis patients. A possible factor on the etiology of uremic anemia. Nepron 1990; 55:251-3.

[18] Miguel A, Miguel A, Linares M, et al. Evidence of an increased susceptibility to lipid peroxidation on red blood cells of chronic renal failure. Nephron 1988; 50:64-5.

[19] Halliwell B, Gutteridge JMC. Free Radicals in Biology and Medicine. Clarendon Press, Oxford. 1989:205-6.

[20] Clemens MR, Bursa-zanetti Z. Lipid abnormalities and peroxidation of erythrocytes in nephrotic syndrome. Nepron 1989; 53:325-9.

[21] Jokes RA, McAlister JM, Prankerd TAJ. Isotope investigation of red cell production and destruction on chronic renal disease. Clin Sci 1956; 15:511-22.

[22] Cotes PM, Pippard MJ, Reid CDL, Wineals CG, Oliver DO, Royston JP. Characterization of the anaemia of chronic renal failure and the mode of its correction by a preparation of human erythropoietin(r-HuEPO). An investigation of the pharmacokinetics of intravenous erythropoietin and its effects on erythrokinetics. Quarterly Journal of Medicine 1989; 262:113-37.

[23] Dong W, Lin JX, Jing GW, Liu YQ. Investigation on SOD in red blood cells from patients with chronic renal failure. Third Conference on free Redical Biology and Medicine(abs). Xiamen, China, 1991:345.

\section{Received 6-4-1993 Revised 14-12-1993 Accepted 7-1-1994}

